\title{
PI3K inhibition sensitizes EGFR wild-type NSCLC cell lines to erlotinib chemotherapy
}

\author{
XIN ZHOU $^{1 *}$, XIAOWEN WANG $^{2 *}$, HONGGE ZHU $^{1}$, GUOMIN GU $^{1}$, \\ YIYI ZHAN ${ }^{1}$, CHUNLING LIU $^{1}$ and GANG SUN ${ }^{3}$ \\ Departments of ${ }^{1}$ Second Pulmonary Medicine, ${ }^{2}$ Second Breast Surgery and ${ }^{3}$ Breast, Head and Neck Surgery, \\ Affiliated Tumor Hospital of Xinjiang Medical University, Urumqi, Xinjiang 830011, P.R. China
}

Received March 23, 2019; Accepted January 14, 2020

DOI: $10.3892 /$ etm.2020.9441

\begin{abstract}
Tyrosine kinase inhibitors (TKIs) bring significant benefits for patients with cancers harboring epidermal growth factor receptor (EGFR) mutations. However, after treatment for a certain period, most patients ultimately acquire resistance. Numerous studies indicated that PI3K has an important role in tumor cell growth and drug sensitivity. Furthermore, inhibition of PI3K may lead to sensitization of non-small cell lung cancer (NSCLC) cells to EGFR-TKIs. The aim of the present study was to explore whether LY294002, an inhibitor of PI3K, is able to improve the sensitivity of NSCLC cell lines with wild-type EGFR to the EGFR-TKI erlotinib. An MTT assay was used to examine the effect of combined treatment with LY294002 and erlotinib on cell survival of two EGFR wild-type NSCLC cell lines, NCI-H661 and NCI-H460. Furthermore, flow cytometry was used to assess apoptosis in NCI-H661 and NCI-H460 cells after treatment with erlotinib and LY294002. In addition, the expression of downstream proteins was detected by western blot analysis. The results indicated that the number of viable NCI-H661 and NCI-H460 cells was dose-dependently reduced by erlotinib or LY294002. Compared to treatment with erlotinib alone, the cell apoptosis was enhanced if combined treatment of erlotinib and LY294002 was performed in NCI-H661 cells. Furthermore, combination treatment of erlotinib and LY294002 resulted in a significant reduction of phosphorylated p70S6K levels in NCI-H661 [PI3K catalytic subunit alpha (PI3KCA) wild-type] cells. However, this phenomenon was not observed in the NCI-H460 cell line (PIK3CA mutant-type). In conclusion,
\end{abstract}

Correspondence to: Dr Gang Sun, Department of Breast, Head and Neck Surgery, Affiliated Tumor Hospital of Xinjiang Medical University, 789 Suzhou East Street, Urumqi, Xinjiang 830011, P.R. China

E-mail: 1518437725@qq.com

${ }^{*}$ Contributed equally

Key words: non-small cell lung cancer, epidermal growth factor receptor, inhibitor, PI3K inhibitor, p70S6K the present study indicated that inhibition of PI3K may have the potential to improve the sensitivity of NSCLC cells to an EGFR-TKI. However, the therapeutic effect may depend on the mutation status of PIK3CA.

\section{Introduction}

Lung cancer is the leading cause of cancer-associated mortality worldwide (1). Approximately $85 \%$ of patients with non-small cell lung cancer (NSCLC) eventually progress to an advanced or metastatic stage of the disease, which is associated with poor prognosis. Chemotherapy remains the only viable option for prolonging survival $(2,3)$. In order to improve survival, studies have focused on exploring novel therapeutic approaches targeting the molecular mechanisms that regulate tumor cell growth.

NSCLCs harboring an activating epidermal growth factor receptor (EGFR) kinase domain mutation may be treated with EGFR tyrosine kinase inhibitors (TKIs), including erlotinib and gefitinib (4-6). However, the majority of patients who initially respond to EGFR inhibitors ultimately develop resistance to therapy, resulting in progression and relapse $(7,8)$. Two major mechanisms are thought to be involved in the process of resistance. First, genetically secondary EGFR mutations may lead to resistance to TKIs. Furthermore, activation of bypass survival tracks via other receptor tyrosine kinases (RTKs), or alternative downstream components may also account for the acquired resistance $(9,10)$. Mutational activation of downstream signaling components, including $\mathrm{PI} 3 \mathrm{~K} / \mathrm{Akt}$ or mitogen-activated protein kinase kinase/extracellular signal-regulated kinase, which was independent on the EGFR, was identified as a novel mechanism of TKI resistance. The PI3K/Akt signaling pathway is involved in oncogenesis, tumor cell differentiation, proliferation and apoptosis $(11,12)$. Certain studies have indicated that the PI3K/AKT signaling pathway is implicated in the evasion of the inhibitory effects of EGFR-TKIs. Studies have suggested that this signaling pathway has an important role in the occurrence of resistance to EGFR-TKIs in NSCLC cells $(13,14)$. Therefore, targeting the key proteins of the PI3K signaling pathway by inhibitors is a strategy that is being evaluated as a potential cancer therapy. Furthermore, inhibition of the key proteins of this pathway may improve sensitization of NSCLC cells to EGFR-TKI. 
Combination of a TKI and PI3K inhibitor has been introduced as a therapeutic intervention in cancers harboring PIK3CA mutations (15).

LY294002, a PI3K inhibitor, has been demonstrated to potentiate the anti-myeloma activity of homoharringtonine (16). Furthermore, LY294002 increased the chemosensitivity of pancreatic carcinoma cells to gemcitabine $(17,18)$. However, whether LY294002 is able to improve the sensitivity of NSCLC to erlotinib has remained elusive. In the present study, it was assessed whether co-treatment of erlotinib and PI3K inhibitor LY294002 has an enhanced inhibitory efficacy in NSCLC cell lines, in comparison to erlotinib treatment alone. The effect of LY294002 on the sensitivity of NSCLC cell lines to erlotinib was evaluated, so as to provide a theoretical basis for the clinical treatment of NSCLC with EGFR-TKI combined with PI3K inhibitor.

\section{Materials and methods}

Cell culture and reagents. The lung cancer cell lines NCI-H460 and NCI-H661 were purchased from the Type Culture Collection of the Chinese Academy of Sciences and were cultured in Dulbecco's modified Eagle's medium (Corning, Inc.) supplemented with $10 \%$ fetal bovine serum (Ausbian) in an incubator with $5 \% \mathrm{CO}_{2}$ at $37^{\circ} \mathrm{C}$. Erlotinib was supplied by Selleck Chemicals, LY294002 was provided by MedChemExpress and monoclonal antibodies targeting p70S6K(ab32529) or anti-phospho-p70S6K (ab5231) were purchased from Abcam. Anti-GAPDH(sc-32233) and horseradish peroxidase-conjugated anti-rabbit (sc-2004)or anti-mouse IgG(sc-2005) were purchased from Santa Cruz Biotechnology, Inc.

Cell viability assay. Cell viability was determined by MTT assays following the manufacturer's instructions. Cells were seeded in 96-well plates at a density of 4,000 cells/well and allowed to attach overnight. The next day, cells were treated with various concentrations of erlotinib $(0.001,0.003,0.01$, $0.03,1,3,10,30$ or $100 \mu \mathrm{M}), \mathrm{LY} 294002(0.0001,0.0003$, $0.001,0.003,0.01,0.03,1,3$ or $10 \mu \mathrm{M})$ or their combination as indicated. After $72 \mathrm{~h}$ of incubation, $20 \mu \mathrm{l}$ MTT solution $(5 \mathrm{mg} / \mathrm{ml})$ was added to each well and after incubation for $4 \mathrm{~h}$ later, the formazan crystals were dissolved with $100 \mu \mathrm{l}$ DMSO. The absorbance of each well was measured using a spectrophotometer(Tecan infinite) at $490 \mathrm{~nm}$ wavelength. Each experiment was performed in triplicate. Inhibitory effects $=\left(1-\mathrm{OD}\right.$ experimental group $\left./ \mathrm{OD}_{\text {negative control group }}\right) \times 100 \%$.

Cell apoptosis assay. Apoptosis was detected by flow cytometry using the Annexin V FITC Apoptosis Detection kit (eBioscience) according to the manufacturer's instructions. NCI-H460 cells were incubated with erlotinib $(10 \mu \mathrm{M})$, LY294002 $(10 \mu \mathrm{M})$ or their combination for $72 \mathrm{~h}$. NCI-H661 cells were incubated with erlotinib $(3 \mu \mathrm{M})$, LY294002 $(10 \mu \mathrm{M})$ or their combination for $72 \mathrm{~h}$. The harvested cells were washed with pre-cooled PBS three times and resuspended in $1 \mathrm{X}$ Binding Buffer. Subsequently, the cells were stained with Annexin V-APC using a commercial kit (eBioscience), samples were determined by flow cytometry on a FACSort (BD Biosciences) and analyzed using CellQuest software.
Western blot analysis. The protein levels of p70S6K and p-p70S6K in the control group, erlotinib group, LY294002 group and the combined erlotinib and LY294002 group were examined using western blot analysis. NCI-H460 and NCI-H661 cells were cultured for $72 \mathrm{~h}$ and treated with erlotinib, LY294002 or their combination at the indicated concentrations. Cells were lysed in radioimmunoprecipitation assay lysis buffer and lysates were sonicated for $10 \mathrm{sec}$ and centrifuged at $12,000 \mathrm{x} \mathrm{g}$ for $15 \mathrm{~min}$ at $4^{\circ} \mathrm{C}$. Protein concentrations were determined using a BCA Protein Assay Kit(Beyotime). Total protein in each group (30 $\mu \mathrm{g}$ per lane) was separated using $10 \%$ SDS-PAGE and transferred to polyvinylidene difluoride membranes (EMD Millipore). The membranes were blocked with $5 \%$ nonfat milk for $2 \mathrm{~h}$ at room temperature and then incubated with anti-p-p70S6K or anti-p70S6K antibodies at $4^{\circ} \mathrm{C}$ overnight. Subsequently, the membranes were incubated with the appropriate secondary antibodies conjugated to horseradish peroxidase for $1.5 \mathrm{~h}$ at $37^{\circ} \mathrm{C}$. Protein signals were visualized using the enhanced chemiluminescence western blot analysis system.

Statistical analysis. Statistical significance of differences between drug treatment groups and the control group was determined by one-way analysis of variance with Bonferroni's multiple-comparison test using GraphPad Prism 5 (GraphPad Software, Inc.). All values are expressed as the mean \pm standard deviation. $\mathrm{P}<0.05$ was considered to indicate a statistically significant difference.

\section{Results}

Effects of erlotinib and LY294002 on the growth of NSCLC cells. The inhibition rate of erlotinib or LY294002 on two NSCLC cell lines, of which NCI-H661 was PI3K catalytic subunit alpha (PI3KCA) wild-type and NCI-H460 was PIK3CA mutant-type, was examined using an MTT assay. First, the $\mathrm{IC}_{50}$ of erlotinib was compared between the cell lines (Fig. 1A). The $\mathrm{IC}_{50}$ value of erlotinib was $12.43 \mu \mathrm{M}$ for NCI-H460 and 13.97 $\mu \mathrm{M}$ for NCI-H661, indicating that the sensitivity of these cells to erlotinib is not associated with the mutation status of PIK3CA, but on the genotype regarding EGFR.

The inhibitory effect of LY294002 on the cell growth activity of these cell lines with different mutation status of PIK3CA was also determined (Fig. 1B). The results indicated that cell growth inhibition occurred in a dose-dependent manner. Furthermore, the inhibitory effect of LY294002 on NCI-H661 cells was better than that on NCI-H460 cells, suggesting that the effect of LY294002 may be influenced by the mutation status of PIK3CA.

Combined treatment with erlotinib and LY294002 enhances the inhibitory effect of either drug alone on NCI-H460 and NCI-H661 cells. To examine whether PI3K inhibitor LY294002 is able to enhance the sensitivity of NSCLC cells to erlotinib, the combined effect of erlotinib and LY294002 on NCI-H460 and NCI-H661 cell viability was detected using an MTT assay. As presented in Fig. 2, compared with LY294002 $(10 \mu \mathrm{M})$ or erlotinib $(10 \mu \mathrm{M})$ treatment alone, combined treatment with LY294002 $(10 \mu \mathrm{M})$ and erlotinib $(10 \mu \mathrm{M})$ caused 

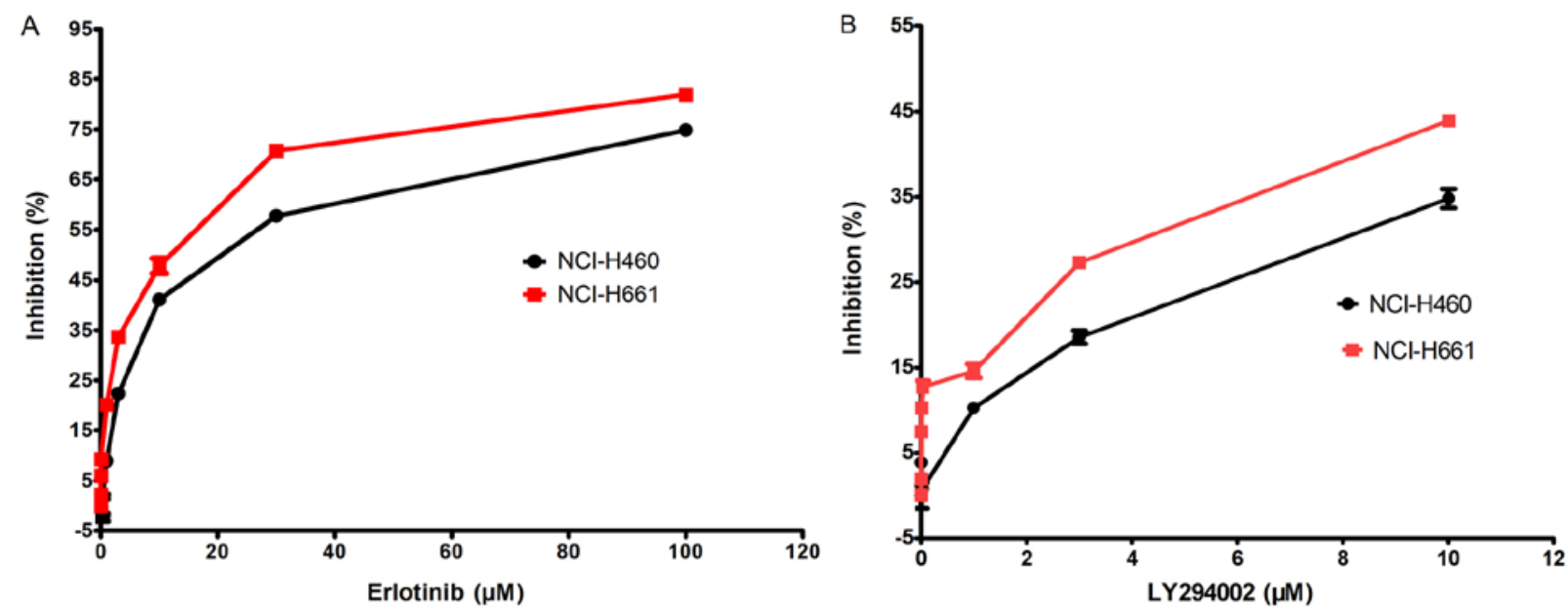

Figure 1. Effect of LY294002 and erlotinib on NCI-H460 and NCI-H661 cell growth. (A) Erlotinib and (B) LY294002 inhibited the growth of NCI-H460 and NCI-H661 cells in a dose-dependent manner. Values are presented as the mean \pm standard error of the mean from three independent experiments.
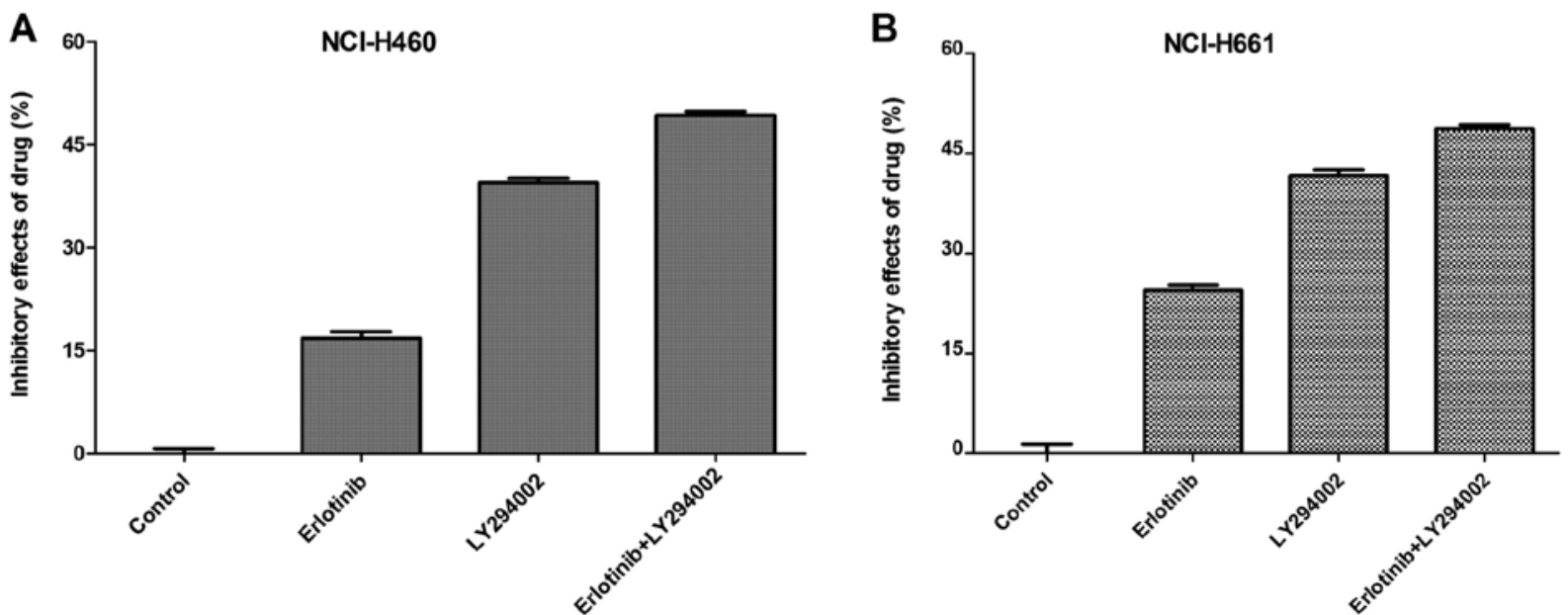

Figure 2. Combined effect of erlotinib and LY294002 to inhibit the growth of NCI-H460 and NCI-H661 cells. (A) NCI-H460 and (B) NCI-H661 cells were treated with erlotinib or LY294002 alone, or a combination of erlotinib and LY294002 at a fixed concentration. Compared with the erlotinib only group and the LY294002 only group, the growth inhibition of the combined treatment of erlotinib and LY294002 on the NCI-H460 and NCI-H661 cells was enhanced.

greater decreases in the amount of viable cells of NCI-H460 $(\mathrm{P}<0.05)$ and NCI-H661 cells $(\mathrm{P}<0.05)$. However, there was no significant difference in the effect of the dual inhibitor therapy between NCI-H460 and NCI-H661 cells $(\mathrm{P}>0.05)$. These results indicated that PI3K inhibitor has the ability to enhance the sensitivity of NSCLC cell lines with wild-type EGFR to erlotinib.

Combined treatment with erlotinib and LY294002 enhances apoptosis of NCI-H661 cells with wild-type PIK3CA. In order to examine the effects of the combined treatment on the NSCLC cells with different mutation status of PIK3CA, the apoptosis of NCI-H661 cells harboring wild-type PI3KAC and NCI-H460 cells with a mutation of PI3KAC in response to the drug treatments was compared. The concentrations of LY294002, erlotinib and their combination for apoptosis were selected based on the results of cell viability. The concentration of drugs were chosen which have the same cell viability between NCI-H661 and NCI-H460. Cell apoptosis in each group was detected using flow cytometry. The results revealed that in NCI-H661 cells, the apoptotic ratio in the combination treatment group was higher than that in each group treated with either drug alone $(\mathrm{P}<0.05$; Fig. $3 \mathrm{~A}$ and $\mathrm{C})$. However, in NCI-H460 cells, the combination treatment did not significantly enhance the percentage of apoptotic cells when compared with that following treatment with LY294002 alone (Fig. 3B and D), suggesting that the effect of LY294002 to enhance apoptosis may be influenced by the mutation status of PIK3CA.

Combination treatment decreases p-p70S6K signaling in NCI-H661 cells. To further investigate the mechanisms of PI3KCA genotype-dependent apoptosis after the combination treatment, the changes in the relevant cell signaling pathway were evaluated. p70S6K is an important downstream effector of PI3K. Western blot analysis was performed to identify the change of p70S6K in the cell lines induced by combination treatment. NCI-H661 harbors wild-type PI3KCA, whereas NCI-H460 is PI3KCA-mutant. Compared to monotherapy, the combination treatment has no influence on p70S6K expression neither in NCI-H460 nor 


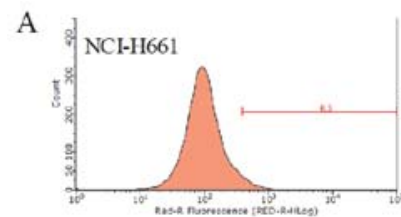

Control

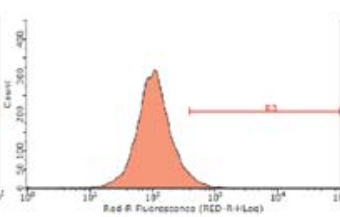

Erotimib

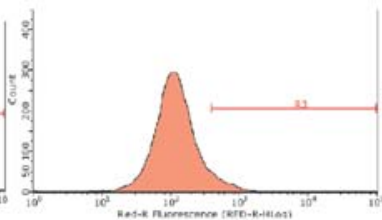

LY294002

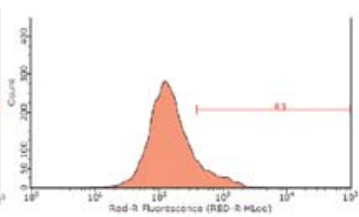

Erlotinib+LY294002

B

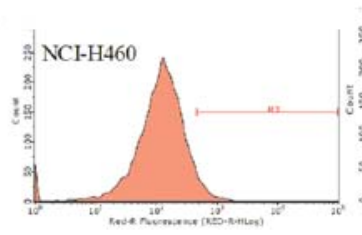

Control

C

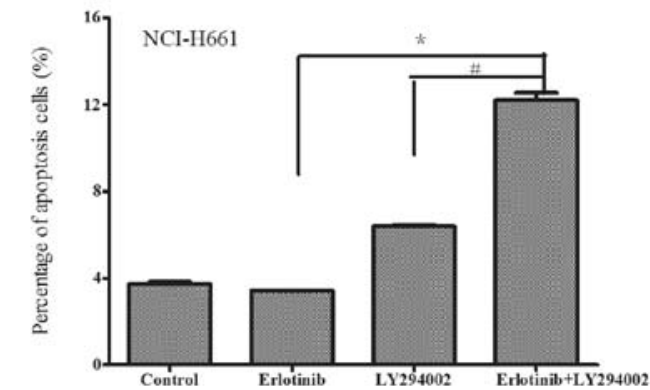

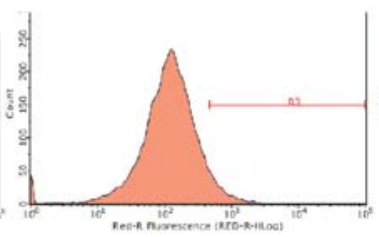

Erlotinib

D

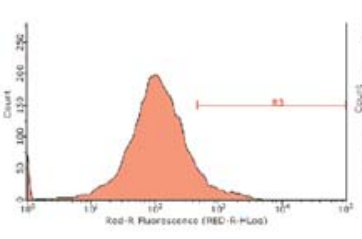

LY294002

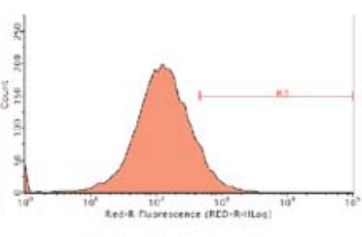

Erlotinib+LY294002

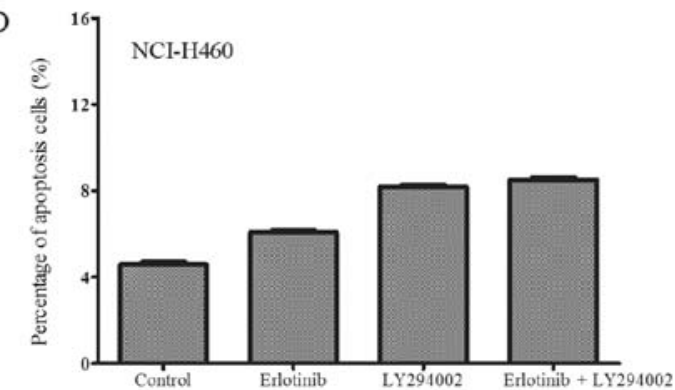

Figure 3. Apoptosis of (A) NCI-H661 and (B) NCI-H460 cells was measured by flow cytometry after treatment with a combination of erlotinib and LY294002. The percentage of apoptotic (C) NCI-H661 and (D) NCI-H460 cells was compared between the monotherapy and combined treatment groups. In NCI-H661 cells, a difference in cell apoptosis was detected with the combined drug treatment. Compared with the control, erlotinib $(3 \mu \mathrm{M})$ or LY294002 (10 $\mu \mathrm{M})$ treatment alone, the cell apoptosis was significantly enhanced after co-treatment. However, no significantly enhanced apoptosis was observed in the NCI-H460 cell line after co-treatment compared to LY294002 treatment alone. Apoptosis of the erlotinib+LY294002 group was significantly increased compared with the Erlotinib or LY294002 groups. * $\mathrm{P}<0.05$ vs. Erlotinib; ${ }^{*} \mathrm{P}<0.05$ vs. LY294002.
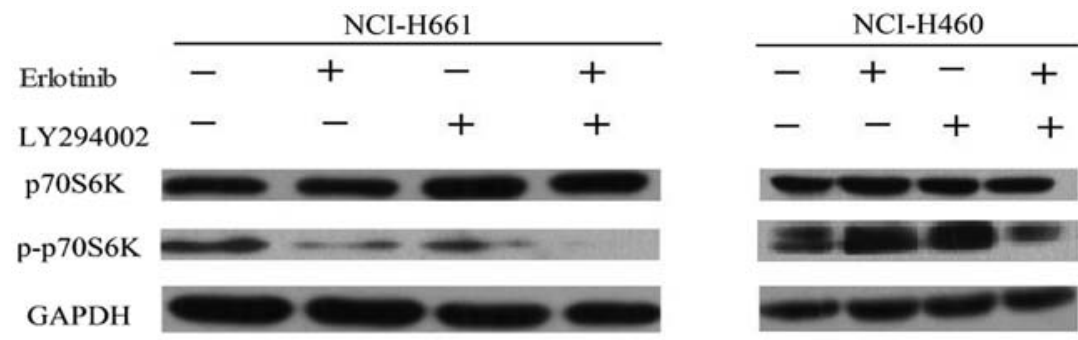

Figure 4. Effects of combined erlotinib and LY294002 treatment on the phosphorylation of p70S6K. NCI-H661 and NCI-H460 cell lines were treated with erlotinib, LY294002 or a combination of the two drugs. The cell extracts were examined by western blot analysis for determination of p-p70S6K. Erlotinib, LY294002 or the combination treatment inhibited p70S6K phosphorylation in the NCI-H661 cell line. While the phosphorylation level of p70S6K was not reduced after monotherapy in the NCI-H460 cell line, combination treatment caused a slight decrease in the level of p-p70S6K. p-p70S6K, phospho-p70S6K.

in NCI-H661 cells. However, combination treatment with erlotinib and LY294002 significantly decreased p-p70S6K levels in the NCI-H661 cell line (Fig. 4). By contrast, the level of p-p70S6K was almost unaffected in NCI-H460 cells. These results suggested that the PI3K signaling pathway has an important role in NSCLC cells. LY294002 was able to enhance the sensitivity of NSCLC cells to erlotinib, particularly for NSCLC cells with wild-type PI3KCA, suggesting that combined treatment may enhance the anti-tumor effect.

\section{Discussion}

Therapy for NSCLC has significantly changed with the discovery of EGFR mutations, as it led to novel treat- ment approaches based on the molecular characteristics of tumors (19). In NSCLC patients with EGFR mutation, treatment with EGFR-TKIs achieved much higher response rates and longer progression-free survival than platinum-based chemotherapies $(20,21)$. However, patients eventually develop acquired resistance after treatment with EGFR-TKIs, typically after $\sim 12$ months. The mechanisms of acquired resistance to EGFR-TKIs have been broadly divided into two categories: Pharmacological and biological mechanisms, including alterations in the drug target, bypass track mechanisms, phenotypic/histologic changes and downstream signaling pathways alterations (22). The PI3K/AKT pathway has a crucial role in oncogenesis and tumor cell growth, and under long-term inhibition of EGFR, the PI3K/AKT pathway may be activated through alternative pathways to maintain tumor cell survival, 
escape TKI attack and generate secondary drug resistance. Therefore, inhibition of the PI3K pathway may increase the sensitization of various tumor cell lines to EGFR-TKIs $(15,23)$. Combined treatment of PI3K inhibitor with EGFR-TKI has been suggested as a novel and effective method for targeted cancer therapy.

LY294002 is a selective inhibitor of PI3K, which may induce apoptosis and inhibit cell proliferation via reducing AKT activation. Numerous studies have indicated that LY294002 is able to improve the sensitivity of various chemotherapy drugs to a variety of tumor cell types $(16-18,24)$. In the present study, it was demonstrated that LY294002 was able to increase the sensitivity of NSCLC cells to erlotinib. The results suggested that the cell viability was reduced in all NSCLC cell lines after treatment with LY294002 or erlotinib. Furthermore, co-treatment with LY294002 and erlotinib amplified cell growth inhibition in two NSCLC cell lines compared with that achieved with LY294002 or erlotinib alone. In order to study the intrinsic molecular mechanism of how LY294002 enhanced the sensitivity of NSCLC cell lines to erlotinib, the NSCLC cells with different status of PIK3CA were selected, NCI-H661 with wild-type PIK3CA and NCI-H460 with PIK3CA-mutant status. The present results suggested that the anti-tumor cell effect of co-treatment with LY294002 and erlotinib on NSCLC cells may be influenced by the mutation status of PIK3CA. The inhibitory effect of LY294002 or erlotinib on NCI-H661 with wild-type PIK3CA was greater than that on NCI-H460 with PIK3CA mutation. Cell apoptosis was evaluated by flow cytometric analysis and the results revealed significantly enhanced apoptosis in NCI-H661 cells treated with a combination of LY294002 and erlotinib compared with that achieved with either LY294002 or erlotinib alone. However, in NCI-H640 cells, apoptosis was not enhanced after combination treatment. Furthermore, in NCI-H661 cells, phosphorylation of p70S6K, an important downstream factor of PI3K, was effectively reduced by combined treatment with the PI3K inhibitor LY294002 and the EGFR-TKI erlotinib, but this result was not obtained in NCI-H640 cell lines. All of these results indicated that the effects of combined treatment with LY294002 and erlotinib on the wild-type EGFR cells were closely linked to the genetic background of PIK3CA.

In conclusion, the present study suggests that inhibiting EGFR may be more effective if combined with selective inhibition of PI3K/AKT pathways for treating wild-type EGFR and PIK3CA wild-type NSCLC cells. The PI3K-AKT pathway is an important mechanistic constituent underlying drug resistance and provides potential targets that hold promise for reversal of drug resistance. The present study provided a novel idea for combining PI3K/AKT and EGFR inhibitors for the treatment of wild-type EGFR and PIK3CA NSCLC in clinical trials for patients with NSCLC. However, the LY294002 and erlotinib combination was only administered in vitro. Additional studies are necessary to understand the efficacy of LY294002 combined with erlotinib on NSCLC in vivo. In addition, further investigations are warranted to determine the potential underlying molecular mechanisms.

\section{Acknowledgements}

Not applicable.

\section{Funding}

The present study was supported by a grant from The National Natural Science Foundation of Xinjiang Uygur Autonomous Region (grant no. 2016D01C366).

\section{Availability of data and materials}

The datasets used and/or analyzed during the current study are available from the corresponding author on reasonable request.

\section{Authors' contributions}

GS, CL, ZX and XW conceived the study, designed the experiments and interpreted the results. ZX, XW, HZ and YZ performed laboratory experiments and data analysis. GG was involved in data acquisition and data analysis. ZX and GG were substantially involved in writing and revising the manuscript. All authors read and approved the final manuscript and agreed to be accountable for all aspects of the work.

\section{Ethics approval and consent to participate}

Not applicable.

\section{Patient consent for publication}

Not applicable.

\section{Competing interests}

The authors declare that they have no competing interests.

\section{References}

1. Jeannot V, Busser B, Brambilla E, Wislez M, Robin B, Cadranel J, Coll JL and Hurbin A: The PI3K/AKT pathway promotes gefitinib resistance in mutant KRAS lung adenocarcinoma by a deacetylase-dependent mechanism. Int J Cancer 134: 2560-2571, 2014.

2. Mouradian M, Kikawa KD, Johnson ED, Beck KL and Pardini RS: Key roles forGRB2-associated-binding protein1, phosphatidylinositol-3-kinase, cyclooxygenase 2, prostaglandin E2 and transforming growth factor alpha in linoleic acid-inducedupregulation of lung and breast cancer cell growth. Prostaglandins Leukot Essent Fatty Acids 90: 105-115, 2014.

3. Brückl W, Tufman A and Huber RM: Advanced non-small cell lung cancer (NSCLC) with activating EGFR mutations: First-line treatment with afatinib and other EGFR TKIs. Expert Rev Anticancer Ther 17: 143-155, 2017.

4. Paez JG, Jänne PA, Lee JC, Tracy S, Greulich H, Gabriel S, Herman P, Kaye FJ, Lindeman N, Boggon TJ, et al: EGFR mutations in lung cancer: Correlation with clinical response to gefitinib therapy. Science 304: 1497-1500, 2004.

5. Lynch TJ, Bell DW, Sordella R, Gurubhagavatula $S$, Okimoto RA, Brannigan BW, Harris PL, Haserlat SM, Supko JG, Haluska FG, et al: Activating mutations in the epidermal growth factor receptor underlying responsiveness of non-small-cell lung cancer to gefitinib. N Engl J Med 350: 2129-2139, 2004.

6. Mok TS, Wu YL, Thongprasert S, Yang CH, Chu DT, Saijo N, Sunpaweravong P, Han B, Margono B, Ichinose Y, et al: Gefitinib or carboplatin-paclitaxel in pulmonary adenocarcinoma. N Engl J Med 361: 947-957, 2009.

7. Engelman JA and Settleman J: Acquired resistance to tyrosine kinase inhibitors during cancer therapy. Curr Opin Genet Dev 18: 73-79, 2008.

8. Matikas A, Mistriotis D, Georgoulias V and Kotsakis A: Current and future approaches in the management of non-small-cell lung cancer patients with resistance to EGFR TKIs. Clin Lung Cancer 16: 252-261, 2015 . 
9. Jakobsen KR, Demuth C, Sorensen BS and Nielsen AL: The role of epithelial to mesenchymal transition in resistance to epidermal growth factor receptor tyrosine kinase inhibitors in non-small cell lung cancer. Transl Lung Cancer Res 5: 172-182, 2016.

10. Zhou Q, Yang JJ, Chen ZH, Zhang XC, Yan HH, Xu CR, Su J, Chen HJ, Tu HY, Zhong WZ, et al: Serial cfDNA assessment of response and resistance to EGFR-TKI for patients with EGFR-L858R mutant lung cancer from a prospective clinical trial. J Hematol Oncol 9: 86, 2016.

11. Gohr K, Hamacher A, Engelke LH and Kassack MU: Inhibition of PI3K/Akt/mTOR overcomes cisplatin resistance in the triple negative breast cancer cell line HCC38. BMC Cancer 17: 711, 2017.

12. Martini M, De Santis MC, Braccini L, Gulluni F and Hirsch E: PI3K/AKT signaling pathway and cancer: An updated review. Ann Med 46: 372-383, 2014.

13. Li H, Schmid-Bindert G, Wang D, Zhao Y, Yang X, Su B and Zhou C: Blocking the PI3K/AKT and MEK/ERK signaling pathways can overcome gefitinib-resistance in non-small cell lung cancer cell lines. Adv Med Sci 56: 275-284, 2011.

14. Heavey S, O'Byrne KJ and Gately K: Strategies for co-targeting the PI3K/AKT/mTOR pathway in NSCLC. Cancer Treat Rev 40: 445-456, 2014

15. Kang XH, Xu ZY, Gong YB, Wang L, Wang Z-Q, Xu L, Cao F and Liao M: Bufalin reverses HGF-induced resistance to EGFR-TKIs in EGFR mutant lung cancer cells via blockage of Met/PI3k/Akt pathway and induction of apoptosis. Evid Based Complement Alternat Med 2013: 243859, 2013.

16. Chen P, Wen X, Wang B, Hou D, Zou H, Yuan Q, Yang H, Xie J and Huang H: PI3K/Akt inhibitor LY294002 potentiates homoharringtonine antimyeloma activity in myeloma cells adhered to stromal cells and in SCID mouse xenograft. Ann Hematol 97: 865-875, 2018

17. Mao Y, Xi L, Li Q, Wang S, Cai Z, Zhang X and Yu C: Combination of PI3K/Akt Pathway Inhibition and Plk1 Depletion Can Enhance Chemosensitivity to Gemcitabine in Pancreatic Carcinoma. Transl Oncol 11: 852-863, 2018.

18. Wang Y, Kuramitsu Y, Baron B, Kitagawa T, Tokuda K, Akada J, Maehara SI, Maehara Y and Nakamura K: PI3K inhibitor LY294002, as opposed to wortmannin, enhances AKT phosphorylation in gemcitabine-resistant pancreatic cancer cells. Int J Oncol 50: 606-612, 2017.
19. Russo A, Franchina T, Ricciardi GR, Picone A, Ferraro G, Zanghì M, Toscano G, Giordano A and Adamo V: A decade of EGFR inhibition in EGFR-mutated non small cell lung cancer (NSCLC): Old successes and future perspectives. Oncotarget 6: 26814-26825, 2015.

20. Rosell R, Carcereny E, Gervais R, Vergnenegre A, Massuti B, Felip E, Palmero R, Garcia-Gomez R, Pallares C, Sanchez JM, et al; Spanish Lung Cancer Group in collaboration with Groupe Français de Pneumo-Cancérologie and Associazione Italiana Oncologia Toracica: Erlotinib versus standard chemotherapy as first-line treatment for European patients with advanced EGFR mutation-positive non-small-cell lung cancer (EURTAC): A multicentre, open-label, randomised phase 3 trial. Lancet Oncol 13: 239-246, 2012.

21. Russo A, Franchina T, Ricciardi GRR, Smiroldo V, Picciotto M, Zanghì M, Rolfo $\mathrm{C}$ and Adamo V: Third generation EGFR TKIs in EGFR-mutated NSCLC: Where are we now and where are we going. Crit Rev Oncol Hematol 117: 38-47, 2017.

22. Camidge DR, Pao W and Sequist LV: Acquired resistance to TKIs in solid tumours: Learning from lung cancer. Nat Rev Clin Oncol 11: 473-481, 2014.

23. Kuger S, Graus D, Brendtke R, Günther N, Katzer A, Lutyj P, Polat B, Chatterjee M, Sukhorukov VL, Flentje M, et al: Radiosensitization of glioblastoma cell lines by the dual PI3K and mTOR inhibitor NVP-BEZ235 depends on drug-irradiation schedule. Transl Oncol 6: 169-179, 2013.

24. Xie X, Tang B, Zhou J, Gao Q and Zhang P: Inhibition of the PI3K/Akt pathway increases the chemosensitivity of gastric cancer to vincristine. Oncol Rep 30: 773-782, 2013.

This work is licensed under a Creative Commons Attribution-NonCommercial-NoDerivatives 4.0 International (CC BY-NC-ND 4.0) License. 